\title{
APPLICATION OF ADDITIONAL INSULATION TO ETICS ON SURFACES WITH BIOCORROSION
}

\author{
NaĎa Antošová, Patrik ŠŤastný*, Marek Petro, Štefan Krištofič \\ Slovak University of Technology in Bratislava, Faculty of Civil Engineering, Department of Building Technology, \\ Radlinského 11, 81005 Bratislava, Slovakia \\ * corresponding author: patrik.stastny@stuba.sk
}

\begin{abstract}
The paper presents partial outputs from an experiment that demonstrated the impact of applying an additional insulation on an existing contact insulation system with a green-algae surface. The aim was mainly to detect the development of microorganisms in the gap between the original and the new insulation. The existing ETICS on the polystyrene-based contact thermal insulation system and EPS-based additional thermal insulation were used in the experiment. A theoretical modelling of temperature conditions showed that this type of doubling the insulation presented the highest risk of condensation of water in the gap between the insulation layers and that these conditions presented suitable humidity conditions for the growth of microorganisms. The reason for the experiment is to demonstrate the need to eliminate microorganisms before applying an additional thermal insulation to surfaces with biocorrosion. This is especially the case where EPS is used. The temperature and humidity parameters obtained during the experiment can be used to model the moisture regime in the gap of other types of insulations (e. g. MW, PUR, PIR.)
\end{abstract}

KEYWORDS: Biocorrosion, external thermal insulation system, repair and maintenance of ETICS.

\section{INTRODUCTION}

Facades being attacked by microorganisms is a worldwide problem, which is already known to cause a deterioration of the characteristics of external walls. This is why an investigation and analysis of such a biological activity is necessary. The analysis is also necessary in order to examine and ensure sustainability, a topic that is at the forefront of scientific as well as societal discussions. Many publications focus on sustainability, which is a very wide concept that has been considered from many angles - including the use of wooden structures in construction [1-4] and various other topics [5, 6]

The hydrothermal behaviour of facades and new methods for repairing biocorroded facades [7, 8] are being investigated by a number of world-renowned authors [9. Some articles [10] focus on examining and assessing the status of external walls, in particular, the joints between the layers and their real physical and mechanical parameters. These articles often formulate recommendations on effective testing of the joints that are difficult to reach and suggest strengthening of the joints that are at risk. There are also articles that describe eutrophication, not just of soil, but also of construction materials. One example is the article [11] that describes and analyses experiments regarding eutrophication and biodegradation of construction materials. This article also refers to article [12, which notes how rare studies of accumulation of microorganisms on construction materials are, due to the difficulty in predicting the behaviour of microorganisms and their relationship to construction materials and environmental conditions.
In the mentioned studies, the focus is usually on the humidity around colonized surfaces. This is due to the importance of studying the impact of humidity on surfaces over time. Such humidity is caused by condensation of water on surfaces, following their decrease in temperature as compared to the surrounding air. Such a low temperature of the ETICS surface and its impact over time (which is influenced by a variety of factors) has been described by authors Raschle and Büchli in publication [13. A similar study was carried out by the authors of publication [14] that also focused on the cooling down of the facade surfaces and the associated condensation. The authors note that the cooling of the facade surfaces occurs throughout the whole year, but is most apparent and lasts the longest during autumn. The authors then focus on the creation and development of algae on the facade surface in the autumn period. A similar study was carried out by scientists from the University of Porto, Faculty of Engineering. In their publication [15], they describe a method for risk assessment, titled BIO.MOD 3 , which results in a simple map that classifies each area of Portugal within a three-level scale identifying the risk of a possible colonisation of construction materials by microorganisms. This model does not, however, take into account the increase in humidity from precipitation and water that flows down the structure; nor does it take into account the accumulation of water in various details of the facade. The model can, however, provide valuable information to determine the basis for the plaster materials on the ETICS surface and the necessary level of protection against biocorrosion. 


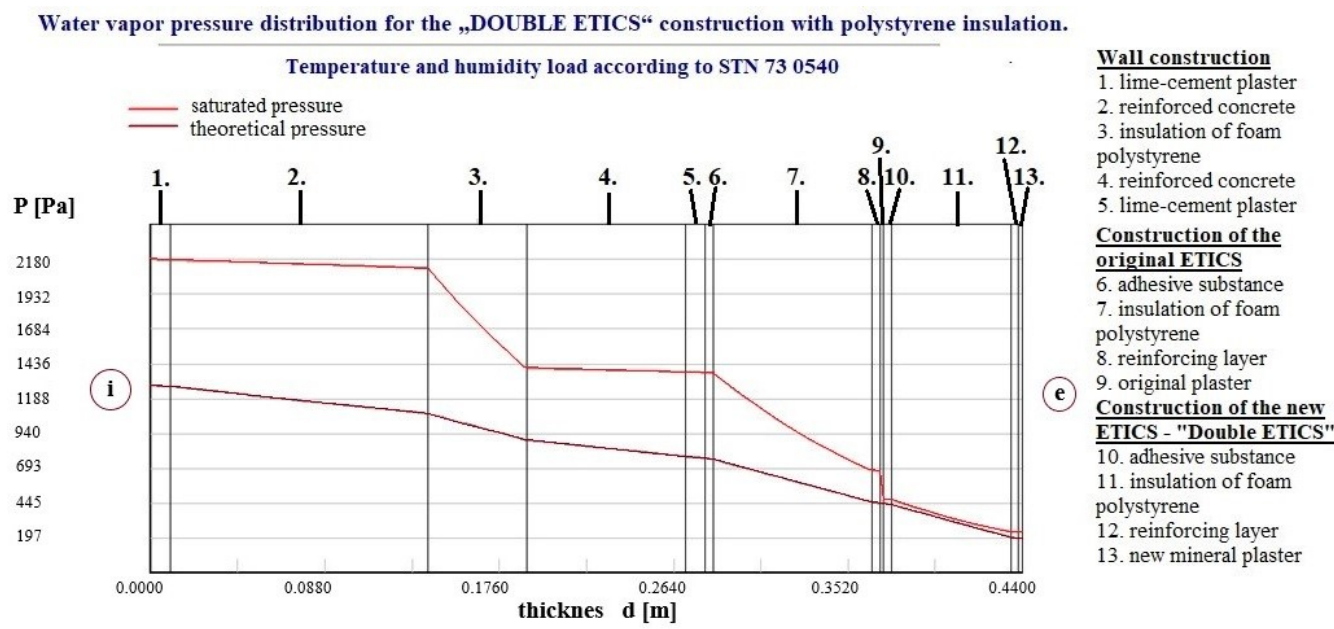

FIGURE 1. Theoretical analysis of steam pressure in DOUBLE ETICS.

It is well known [16] that microbiological activity has an impact on the durability (life span) of construction materials, including the insulation system. The contamination of facades with ETICS is a complex problem that is influenced by a number of interconnected biotic and abiotic conditions of the façade system. The activity and behaviour of these microorganisms on facades with ETICS were studied by botanists from Lund University of Sweden [17], who observed the penetration of the layers with an electron microscopy.

The effects of microorganisms on facades, namely their aesthetic, bio-geo-chemical and bio-geo-physical damage, and the options for removing such microorganisms with special drainage systems, are described in publication 18, from the year 2018. According to [19], in practice, it is necessary to identify all symptoms that contribute to the creation of microorganisms on the plasters typically used. This requires the development of methods for observing the surface of facades over time, and the development of methods for removing the microorganisms. An effective solution for eliminating microorganisms on the surface of insulation systems can be a new radical technology combined with the repair of existing ETICS construction, i. e., the technology of DOUBLE ETICS. No methods for observing the status and behaviour of facades with DOUBLE ETICS have yet been developed or published.

The aim of observing the state of ETICS is to analyse the temperature and humidity conditions in the gap between the original and the new insulation and determine the presence of microorganisms in these gaps depending on the preparation (cleaning and decontamination) of the substrate in the context of worldwide use of a double structure.

The presence of microorganisms also reduces the adhesion of the new layers to the original substrate. Therefore, thorough decontamination of the surface of the original insulation is an important factor for ensuring the mechanical properties of DOUBLE ETICS.

By a quality preparation of the substrate, it is possible to achieve a maximum elimination of the development of microorganisms in the gap between the original and the new construction of ETICS, this fact must be incorporated into the standards and technological rules for the realization of ETICS.

\section{Methodology For the IMPLEMENTATION OF THE EXPERIMENT}

In the first phase of investigating the possible uses of DOUBLE ETICS, the authors carried out an analysis of alternative double insulation systems, and theoretically assessed and modelled their technical and humidity parameters in the layers [21]. Based on the theoretical calculations 22 and previous investigations [23, 24], it is apparent that with an ideal construction method and compliance with all technological regulations, there is a risk of creating an environment suitable for the development of microorganisms in the gaps between the original ETICS and the new insulation (especially if the additional insulation is EPS-based).

Similar conclusions were also reached by the authors when carrying out an analysis according to 20 . In this analysis, a long term condensation of steam in the layers of ETICS was observed, and places where humidity could accumulate were investigated. For comparison purposes, different types and widths of materials and thermal insulation were used. The results of the analysis show that a long term accumulation of humidity can occur in a DOUBLE ETICS system. The humidity conditions recorded in the layers create a suitable environment for the development of microorganisms on the original surface of ETICS. According to German study [20] Figure 2 expresses the content of humidity in layers of DOUBLE ETICS after 5 years from the construction. The profile of the 


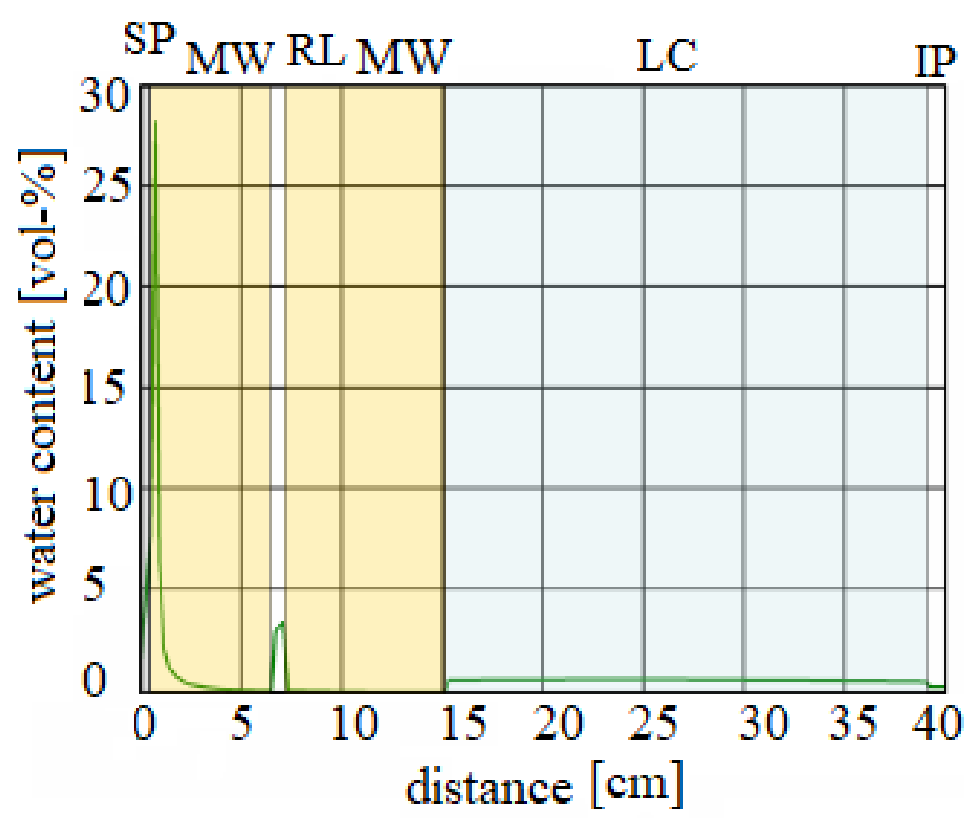

FigURE 2. The content of humidity in layers of DOUBLE ETICS after 5 years from the construction - the German study [20].

water content in variant 3 [20] for DOUBLE ETICS with $\mathrm{MW}$ is in the 19 February in the terminsulation the point of the maximum water content. Composition in ETICS from left: synthetic resin plaster (SP) $0.6 \mathrm{~cm}$, mineral wool (MW) $6 \mathrm{~cm}$, the air gap between the original and the new insulation (RL), mineral plaster (MP) $0.6 \mathrm{~cm}$, mineral wool (MW) $8 \mathrm{~cm}$, expanded concrete (LC) $24 \mathrm{~cm}$, interior plaster (IP) $1.5 \mathrm{~cm}$

The theoretical analysis and results were then verified by an experiment on a selected surface of insulation with biocorrosion. The aim was to investigate the possibility of applying double insulation onto the original ETICS, after recording the existing conditions in the layers of DOUBLE ETICS which could have an impact on the survival and development of biocorrosion on the original facade.

The experiment consisted of three main steps:

- Preparation of surface and application of samples

- Recording the results of temperature and humidity measurements

- Analysis of recorded data and mycologic samples

The thermal and humidity data collected during the one-year experiment were compared with the theoretical calculations carried out. As part of the experiment, samples of additional insulation were placed directly on the block of flats with microorganisms on the original insulation.

\section{Preparation AND APPlication of SAMPLES FOR PLASTER WITH BIOCORROSION}

Samples of a new layer of ETICS (from grey polystyrene with new-generation plasters that are de- clared to have a high biocorrosion resistance) were placed on the existing insulation, which was already affected by biocorrosion. The samples were $30 \times 30 \mathrm{~cm}$ each, see Figure 3 placed in three groups on different bottom layers.

In the case of one sample of group C, DOUBLE ETICS was applied to the entire penetration paint coat without any removal of microorganisms. For other samples, a conservative method for destroying microorganisms was applied. This method should, on the basis of this experiment, be part of the methodology for preparing the bottom layer before the application of double insulation. In group B, the bottom layer was simply treated with a biocide for algae removal. In group $\mathrm{A}$, the bottom layer was treated with biocide and also cleaned with high-pressure water. After the cleaning, samples were taken to determine the level of destroyed microorganisms.

Subsequently, the additional insulation was applied in accordance with [25], applying adhesives on the edges of the insulation plate, in compliance with the current legislation and standards [26]. Measuring probes were placed between the layer of the original insulation and the layer of the new additional insulation. The probes - Testo 176 P1-5 and a canal recorder collected the temperature and humidity data for the period of one year.

Before the additional insulation was applied, a control measurement and sampling of the biological material on the surface of the original insulation was carried out, in a laboratory, to identify the type and extent of microorganisms. This will be used as a baseline at the end of the experiment.

The one sample in group $\mathrm{C}$ - without any cleaning or removal of microorganisms - is a reference sample, 

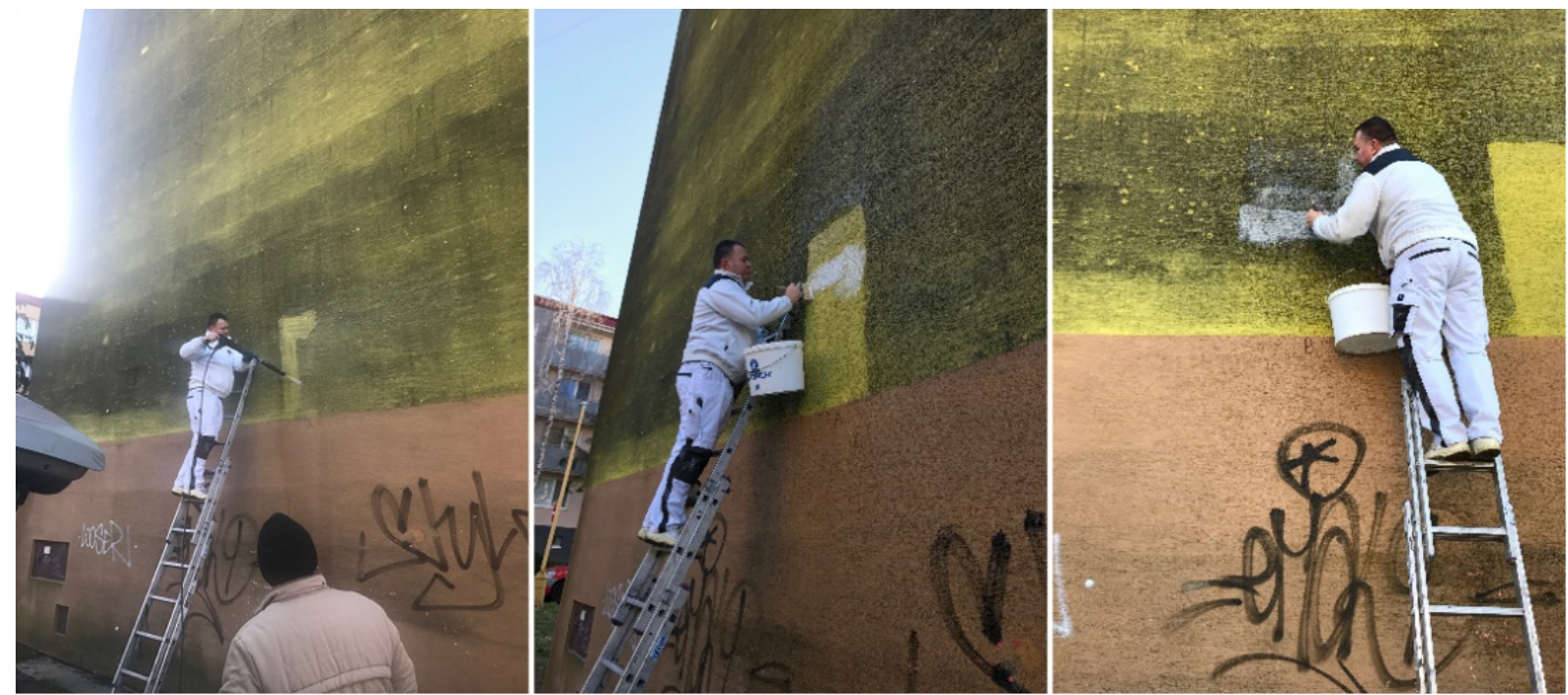

FiguRE 3. Preparation of bottom layer before applying additional insulation.

which was used as part of the experiment to compare the development or reduction of the original microorganisms in the gap.

To ensure objectivity, the biological material was taken from all samples in two phases, before and after any cleaning. The quality of the air in the area was also measured, using a volumetric aeroscope A-AIR-010. After collecting the information about the microorganisms on the bottom layer, a new layer of insulation was applied to each sample in line with the technological rules. To ensure that the groups do not have an impact on each other, they are $1.2 \mathrm{~m}$ apart.

\section{MONITORING OF CRITICAL PARAMETERS IN THE DOUBLE ETICS GAP}

To record the thermal and humidity conditions, an intelligent wireless system was used. The recording of thermal and humidity conditions in the one-year period was made via WeatherHub SmartHome System as well as TFA Temperatur Funksender + Kabelsensor, TFA - Thermo-Hygro Sensor. These recorded the temperature of the exterior, interior and, with the help of the probe, the gap between the layers of the original and the new insulation. Another system was used to measure the exterior and interior humidity. All devices were placed directly on the facade, or (in the case of the interior measurements) in one of the flats in the building.

\section{Results of THE EXPERIMENT}

\subsection{Results of microbiological tests BEFORE THE APPLICATION OF THE SAMPLES}

The collection of the samples was carried out by using a duct tape and drilling a hole with the circumference of $4 \mathrm{~cm}$ and a depth of $6 \mathrm{~cm}$. The samples were placed in a sterile environment. The biological layer on the facade had a significant growth of fungi, algae and even moss. The mycological analysis in the laboratory confirmed the types and extent of microorganisms present on the facade.

Based on the mycological analysis carried out prior to the DOUBLE ETICS being applied, it became apparent that the most common microorganisms on the surface are microscopic fungi. These are a common part of the outside flora in cold humid seasons.

Table 1] is analysed microorganisms in the air and on the construction of the original ETICS. The record of the quantitative representation is the basis for the evaluation of the experiment - a comparative standard for determining the development of microorganisms in the gap between the original and the new ETICS (KTJ - colonies of fungi). Microscopic fungi create a root system, which is perfect for the development of other microorganisms, such as moss and lichen. The root system of these organisms then grows into the surface and its layers. The authors also found microorganisms that can live in gaps of various materials and layers, with only minimal requirements for sunlight.

\subsection{Results FROM THE COLLECTION OF CRITICAL PARAMETERS IN DOUBLE ETICS}

On the basis of the results and collection of parameters, one of the aims of the experiment is to determine the perfect thermal and humidity conditions for the development of microorganisms in the gap between the original and the new insulation. This requires measuring the condensation of water in places where the two layers connect, together with measuring the thermal conditions. The first results show that there are changes between the internal and external environment, which can lead to the creation of a suitable humidity in the gaps and perfect conditions for the development of microorganisms. Over time, there were 


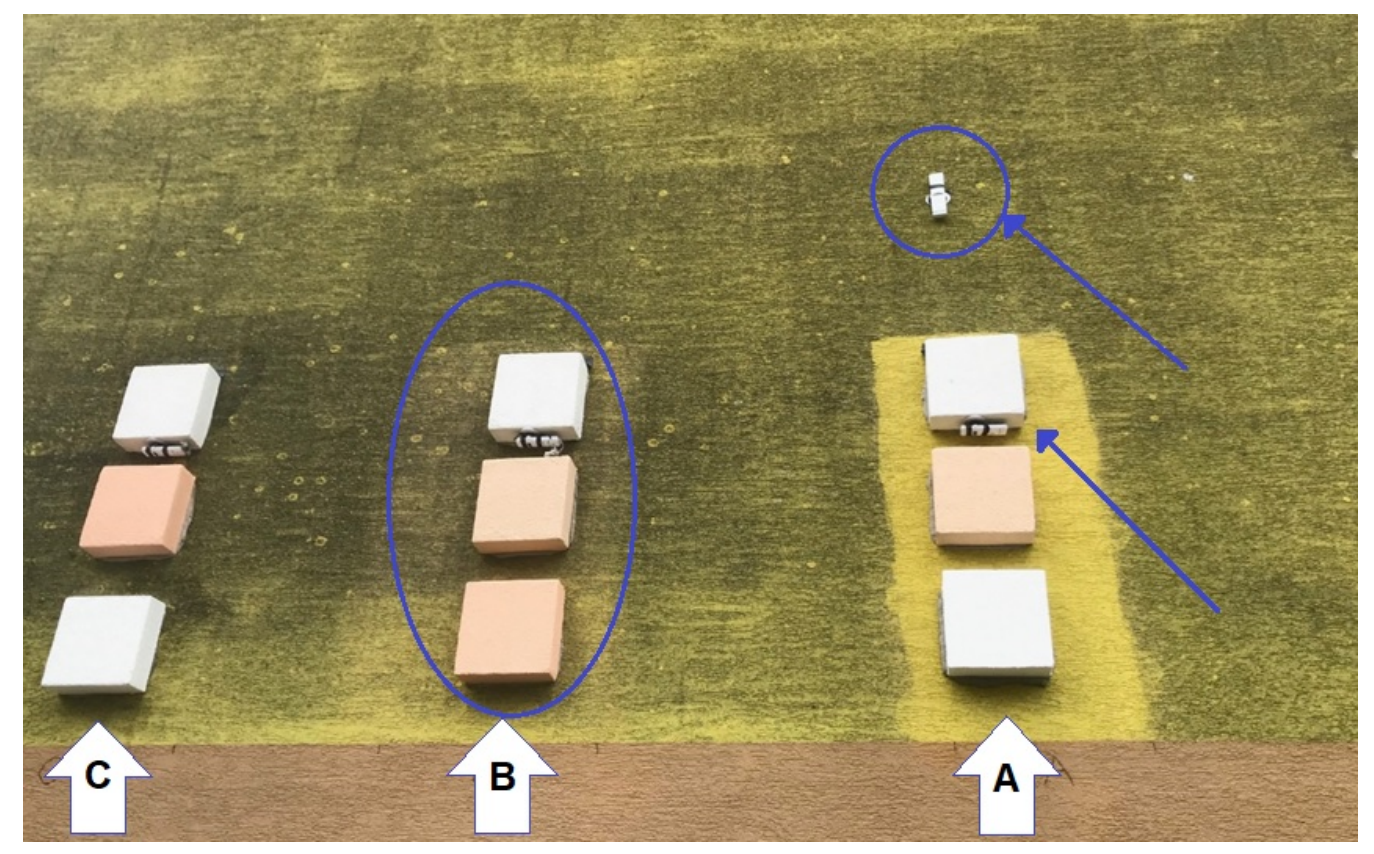

Figure 4. Placement of samples. Arrows denote the clusters of analysed samples - A, B and C used in experiment. $\mathrm{C}$ - reference sample without cleaning, B - sample with decontamination by biocide but not pressure washing, A sample with decontamination by biocide and pressure washing after $24 \dot{\mathrm{h}} \mathrm{rs}$.

\begin{tabular}{|c|c|c|c|}
\hline \multicolumn{4}{|c|}{ Results of qualitative and quantitative analysis of microorganisms: } \\
\hline \multicolumn{2}{|c|}{ Place of sample } & Quantity & Type \\
\hline \multicolumn{2}{|l|}{$\begin{array}{l}\text { Outside } \\
\text { environment }\end{array}$} & $160 \mathrm{KTJ} / \mathrm{m}^{3}$ & $\begin{array}{l}\text { Alternaria sp., Fusarium sp., } \\
\text { Cladosporium cladosporioides, } \\
\text { C.herbarum, Trichothecium } \\
\text { roseum, Aspergillus ochraceus, } \\
\text { yeast, melanized fungi } \\
\text { Dematiaceae }\end{array}$ \\
\hline \multirow{4}{*}{$\begin{array}{l}\text { Surface of } \\
\text { plasters }\end{array}$} & South side - clean & $107 \mathrm{KTJ} / \mathrm{cm}^{2}$ & $\begin{array}{l}\text { Cladosporium cladosporioides, } \\
\text { Penicillium sp. Alternaria sp., } \\
\text { Acremonium sp., Penicillium sp., } \\
\text { Aureobasidium pullulans, } \\
\text { Ulocladium chartarum, sterile } \\
\text { mycelium }\end{array}$ \\
\hline & North side - dirty & $205 \mathrm{KTJ} / \mathrm{cm}^{2}$ & $\begin{array}{l}\text { Penicillium sp., Alternaria sp., } \\
\text { Cladosporium cladosporioides }\end{array}$ \\
\hline & West side - no insulation & $541 \mathrm{KTJ} / \mathrm{cm}^{2}$ & Penicillium sp. \\
\hline & North side - base & $59 \mathrm{KTJ} / \mathrm{cm}^{2}$ & $\begin{array}{l}\text { Cladosporium cladosporioides, } \\
\text { Penicillium sp., Alternaria sp., } \\
\text { Aureobasidium pullulans, } \\
\text { melanized fungi Dematiaceae, } \\
\text { sterile mycelium }\end{array}$ \\
\hline \multirow{3}{*}{ Polystyrene } & South side - clean & $210 \mathrm{KTJ} / \mathrm{cm}^{3}$ & Penicillium sp., Mucor sp. \\
\hline & North side - dirty & $1101 \mathrm{KTJ} / \mathrm{cm}^{3}$ & Penicillium sp. \\
\hline & North side - base & $52 \mathrm{KTJ} / \mathrm{cm}^{3}$ & $\begin{array}{l}\text { Penicillium sp., Cladosporium, } \\
\text { Absidia sp., cladosporioides, } \\
\text { Acremonium sp. }\end{array}$ \\
\hline
\end{tabular}

TABLE 1. The analysis microorganisms in the air and on the construction of the original ETICS. 


\section{Recorded temperatures}

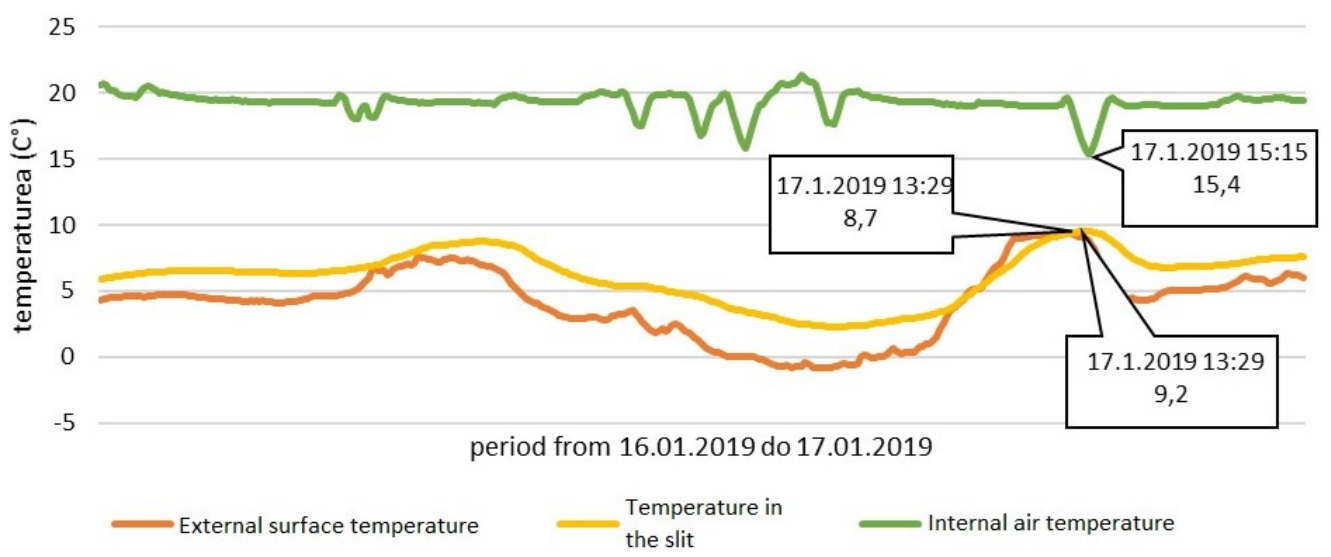

Figure 5. The anomalies of temperature in the gap of DOUBLE ETICS - sample.

\section{Anomalies of temperature in the gap - sample A -}

\subsubsection{9}

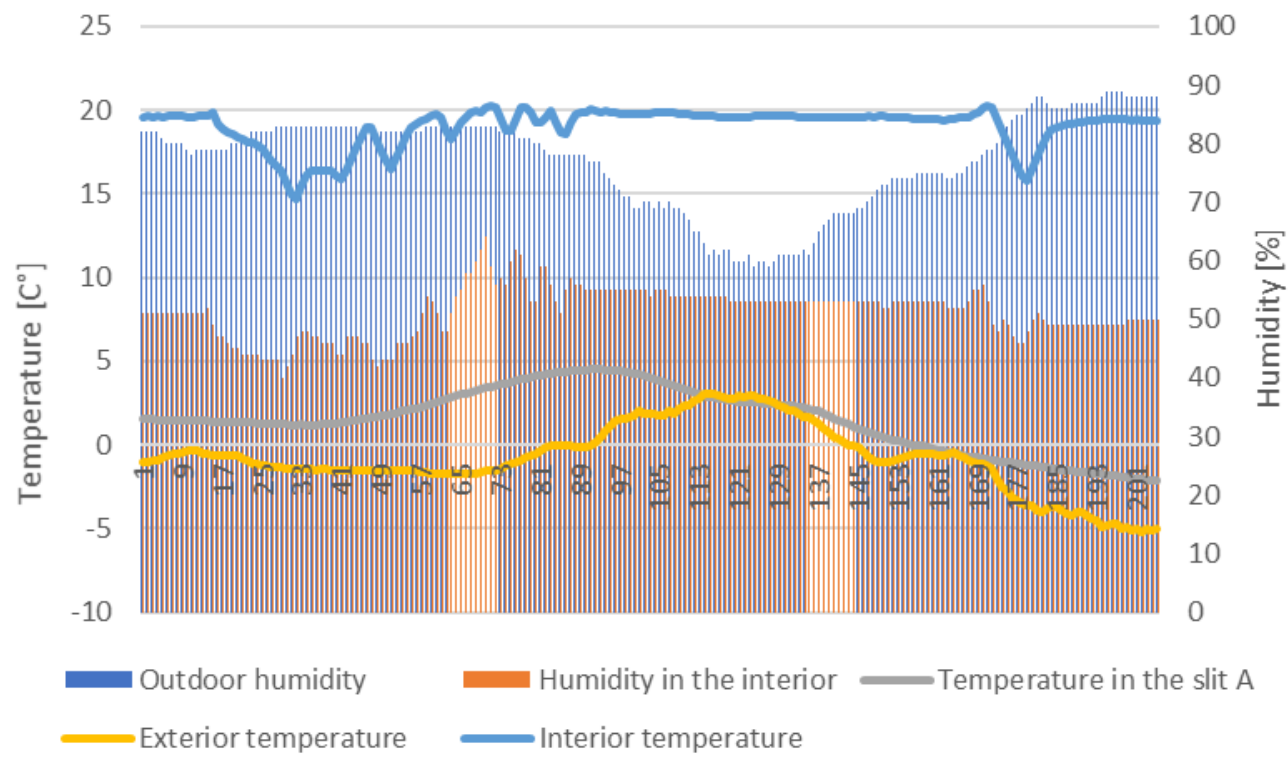

FIGURE 6. Repeated measurement of the decrease in temperature in the gap of DOUBLE ETICS compared to outside temperature - sample A.

occasions when anomalies in temperature (sudden drops in temperature in the gap and sudden rises in temperature on the surface) have been measured in the gap. In particular, on the days when such anomalies occurred, the risk of condensation increased (Figure 5). In the Figure 5 is internal air temperature represented of green colour, red colour represents the temperature on the external surface of the additional ETICS structure. Yellow colour represents the temperature in the gap between the original and the new structure of ETICS. The consequences of a significant reduction of the surface temperature of the structure related to the temperature of the immediate vicinity (e.g., gap temperature) are the same as for the moisture condensation in the summer months on a glass with a cold drink.
The collection of data has now been completed, and the results are currently being analysed further. The data was collected over the period of one year. The samples were removed from the facade of the building at the start of the year 2020 and were moved to a laboratory for a further investigation.

\subsection{Results of microbiological tests AFTER REMOVAL OF SAMPLES}

After removing the second layer of insulation, further samples of biological material were taken in the laboratory. This was done for all groups, A, B and C.

During the mycologic investigation, several types of fungi were found in various phases of development. Based on their demands on humidity [27], these can be split into the following groups: 


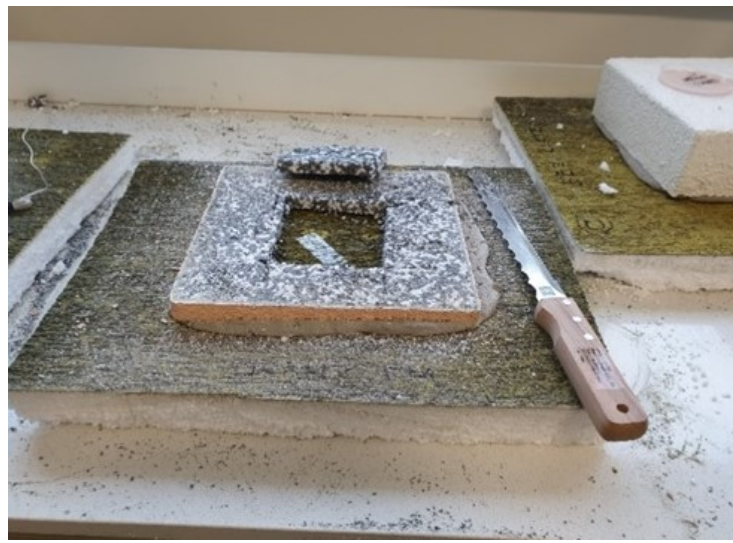

(A).

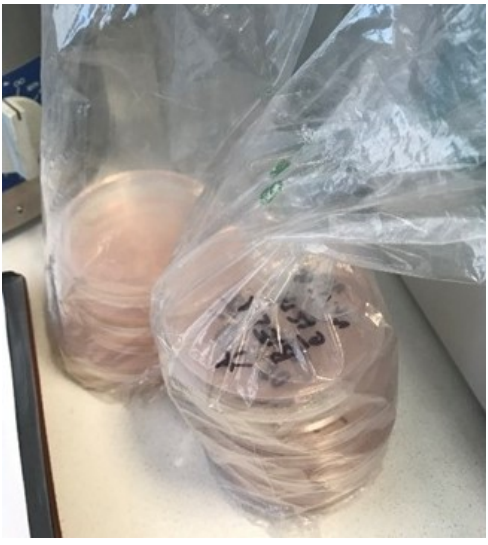

(B).

Figure 7. Removal of second layer of insulation. Sampling of biological material with sampling tape into petri dishes immediately after the opening of the gap.

- Primary colonisers (Cladosporium cladosporioides, Penicillium sp., Botrytis cinerea, Eurotium sp. ) air fungi, present everywhere, that colonise all surfaces including construction materials. All they require for existence is the natural air humidity. Generally, they die in an insufficiently humid environment.

- Secondary colonisers (Alternaria sp., Cladosporium, melanised fungi), fungi which appear in plant biological material (whether alive or dead). They use their own or the plant's dead cells as a source of nourishment, and their development is affected by the humidity of the surface.

- Tertiary colonisers (Rhodotorula sp., Achaetomium strumarum, Scopulariopsis sp.) yeasts and fungi found in plant biological material (whether dead or alive, and whether their own or another plant's). They develop on the original dead primary colonisers. Their development depends on a constant and long term air humidity or humidity of the surface.

The results of the microbiological sample analysis indicate a long-term higher humidity, as shown by the tertiary microorganisms, that were found after the removal of the samples in the gap of the double insulation. Their quantity in each sample before the application of an additional insulation and after the removal of the samples is shown in the Figures 8 and 9 .

\section{DisCussion}

The aim of the experiment was to show the suitability of using DOUBLE ETICS on the surface of the original insulation with biocorrosion. The aim was also to find the connection between the temperature and humidity conditions in the gap between layers, necessary for the development of microorganisms. Different samples were supposed to lead to different results, based on the different preparation of the surface before applying the second layer of insulation.

At the time this article was written, the study and analysis of the results was not yet complete. This requires a validation of a sufficient number of samples with the same parameters, in order to follow statistical rules and standards. However, even now it is possible to confirm the hypothesis about the presence of new microorganisms in the gap between samples taken in group $\mathrm{C}$ (that had the second layer of isolation applied without any preparation or cleaning of the surface). The quantitative difference in microorganisms between groups A and B is minimal.

Mechanical resilience and stability are among the basic expectations that one would have of ETICS. During further laboratory tests, we tested the adhesion of the new layer of insulation to the original layer of ETICS without any cleaning or removal of microorganisms, and with cleaning. This was carried out after the samples were removed from the wall.

Standard ETAG 004 [28] is used to assess the properties of items against the requirements of construction. The original national standard [26] recommends an average adhesion of underlying surface of at least $200 \mathrm{kPa}$ and no lower than $80 \mathrm{kPa}$. The underlying surface is considered to be, according to ETAG, bricks, aerated concrete or other blocks and concrete walls. There is no standard for adhesion of an original layer of ETICS that acts as an underlying layer for further layers of ETICS. The national standard [25, 26] requires the same conditions for both ETICS and DOUBLE ETICS. For this reason, we used the test according to chap. 5.1.4.1.1 in 28] to assess the adhesion of a basic layer to a temperature insulator. The test is carried out on five samples taken from the test wall after temperature and humidity changes (a cycle of interchanging heating and cooling down). The five samples were $50 \times 50 \mathrm{~mm}$ in size, and were cut with an angle grinder through the plaster up to the layer of insulation. Metal squares were then placed and glued with a standardized glue to these areas (Figure 10 . The test was carried out on both the cleaned and not-cleaned areas.

The adhesion was then measured by increasing tensile force from $1 \mathrm{~mm} / \mathrm{min}$ to $10 \mathrm{~mm} / \mathrm{min}$ and recording 


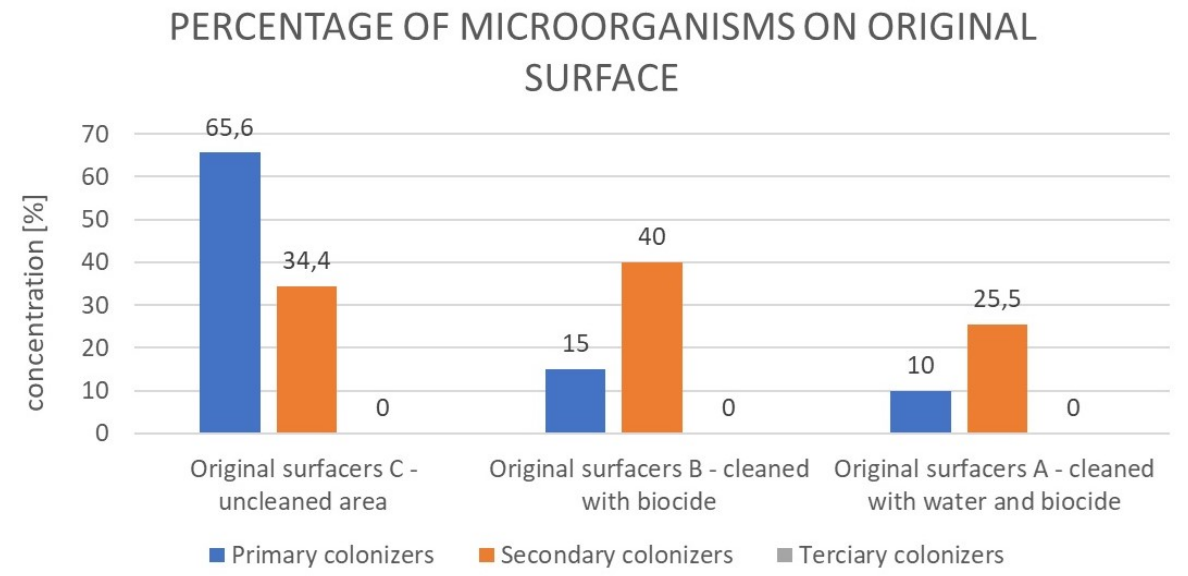

FIGURE 8. The comparison of microorganisms on samples taken before the application of DOUBLE ETICS - without any tertiary colonisers.

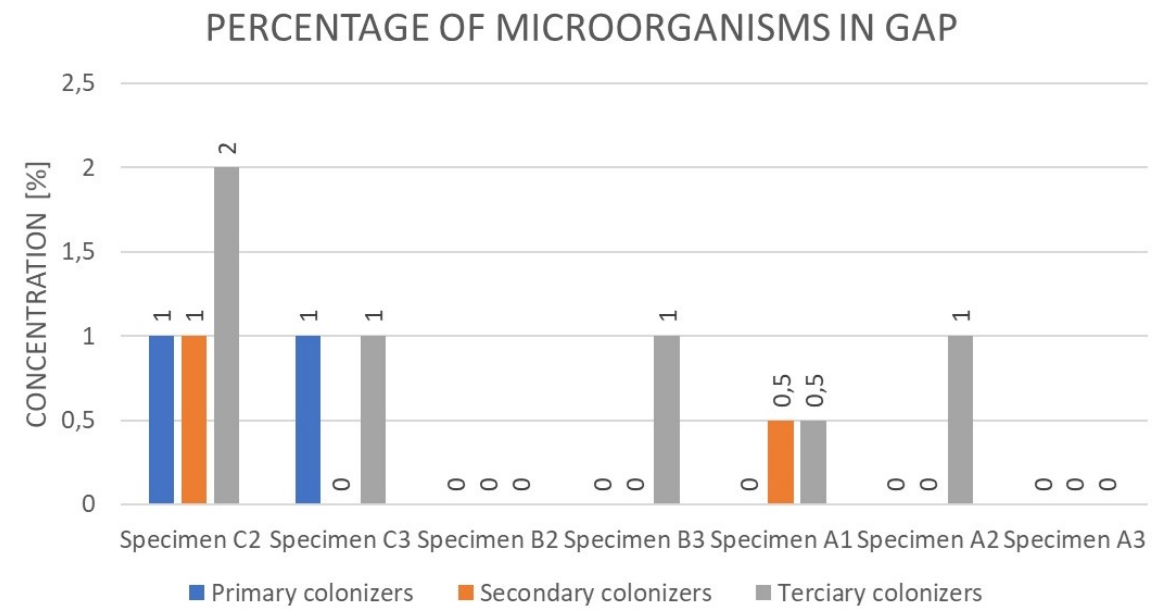

FiguRE 9. The comparison of microorganisms in samples taken from gap between original insulation and new insulation - tertiary colonisers present.

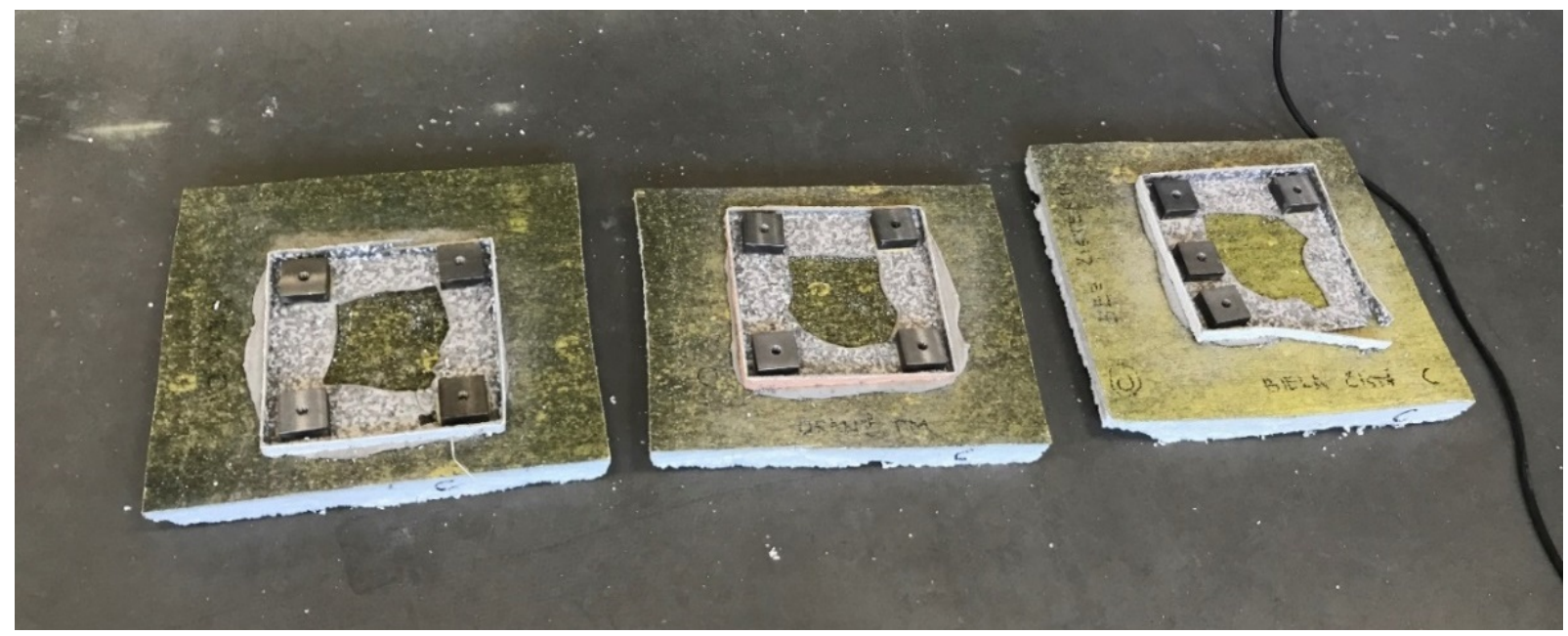

Figure 10. Removal of second layer of insulation. Preparation of samples in each group to test adhesiveness on the sample: from the right, $\mathrm{C}, \mathrm{B}, \mathrm{A}$. 

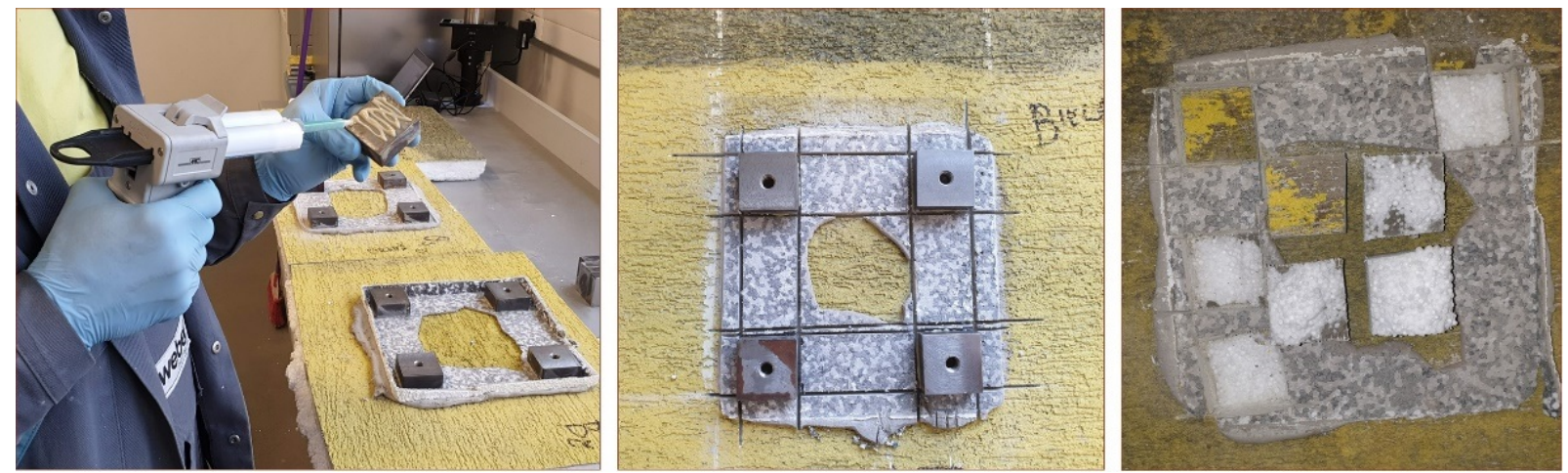

FiguRE 11. Preparation of samples in each group for adhesion tests with a certified device "ConsurTest 5, Serial No. 19763".

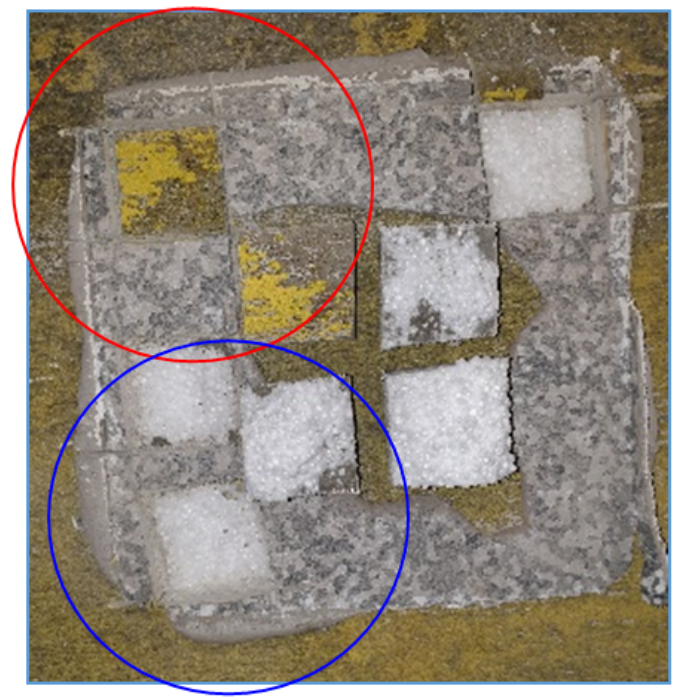

FiguRE 12. Example of visual condition after performing an adhesion test on sample C.

individual and average values. The diagnosis was done with a certified "ConsurTest 5, Serial No. 19763" tester (Figure 11). The average adhesion value should have been at least $0.08 \dot{\mathrm{N}} / \mathrm{mm}^{2}$, in the case of an undamaged insulation layer. In Figure 12 we see a break in the adhesion between the layers of DOUBLE ETICS. Area 1 (red color) - failure of adhesion between the ETICS substrate and the adhesive mortar of the new ETICS. Area 2 (blue color) - breach of adhesion in the insulation of the original ETICS structure.

The experiment confirmed that, as compared with a clean and decontaminated surface, the adhesion to the original plaster with a biological material was significantly lower for many samples, almost outside the values expected by the standards. The differences in adhesion values are interesting, although not yet sufficiently analysed at this stage of the investigation. In order to confirm the results of the experiment, a higher number of samples is required to confirm the lower adhesion.

\section{Conclusions}

The experiment provided the results that were expected and confirmed initial hypotheses about the existence and further development of microorganisms in the gap between original and new ETICS.

The experiment shows the necessity to clean the substrate and perform a decontamination of the original ETICS surface from microorganisms, in order to form a clean substrate for the DOUBLE ETICS.

We also established the impact of microorganisms on the adhesion of the new layer of ETICS, which has decreased. This is just as important as the evidence of the need to clean the surface before applying new layers of ETICS.

The obtained results are important for adjusting the requirements of standards for the realization of the DOUBLE ETICS and technological rules for ETICS manufacturers in our country and also abroad, where a similar experiment has not yet been performed. The obtained results are also important for the inspection during the installation of the double insulation, especially for the thorough cleaning of the substrate before the installation of the second layer of the ETICS composite structure.

The results obtained are sufficient for further use in other scientific experiments assessing the suitability of the use of DOUBLE ETICS to repair existing ET- 


\section{Condition of samples with a positive result to the total number of tests performed}

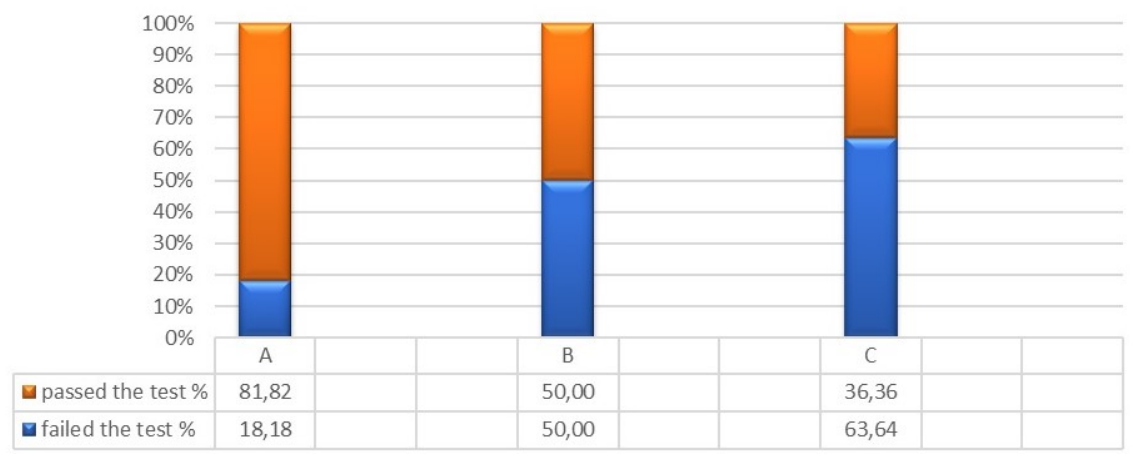

FigURE 13. Evaluation of the results of the adhesion test of the new ETICS structure on samples A, B, C.

ICS. The results of the studies on temperature and humidity conditions in the gap can also be used in a theoretical software modelling of temperature gradients in DOUBLE ETICS (in Slovakia by software programs, such as AREA, TEPLO etc.). The results obtained in the adhesion tests open up possibilities for a further theoretical investigation of the calibration of standard requirements for DOUBLE ETICS adhesion.

\section{ACKNOWLEDGEMENTS}

This paper was created as a research work for the project VEGA N. 1/0511/19.

\section{ReFERENCES}

[1] J. Švajlenka, M. Kozlovská, M. Spišáková. The benefits of modern method of construction based on wood in the context of sustainability. International Journal of Environmental Science and Technology 14:1591-1602, 2017. https://doi .org/10.1007/s13762-017-1282-6

[2] J. Švajlenka, M. Kozlovská. Elements of the fourth industrial revolution in the production of wood buildings. Tehnički glasnik 14(3):365-368, 2020. https://doi.org/10.31803/tg-20200618130201

[3] J. Švajlenka, M. Kozlovská. Houses based on wood as an ecological and sustainable housing alternative case study. Sustainability 10(5):1502, 2018. https://doi.org/10.3390/su10051502.

[4] J. Švajlenka, M. Kozlovská, T. Pošiváková. Biomonitoring the indoor environment of agri-cultural buildings. Annals of Agricultural and Environmental Medicine 25(2):292-295, 2018.

https://doi.org/10.26444/aaem/81314

[5] M. Finkbeiner, E. M. Schau, A. Lehmann, M. Traverso. Towards life cycle sustainability assessment. Sustainability 2(10):3309-3322, 2010. https://doi.org/10.3390/su2103309

[6] R. Lal. Restoring soil quality to mitigate soil degradation. Sustainability 7(5):5875-5895, 2015. https://doi.org/10.3390/su7055875

[7] F. Valentina, A. Diamantia, G. Palleschi. New bio-cleaning strategies on porous building materials affected by biodeterioration event. Applied Surface
Science 256(22):6550-6563, 2010. https://doi.org/10.1016/j.apsusc.2010.04.046.

[8] B. Daniotti, S. L. Spagnolo, R. Galliano. The durability experimental evaluation of photocatalytic cement-based materials. In 12th International Conference on Durability of Building Materials and Components, pp. 212-219. 2011.

[9] K. Breuer, W. Hofbauer, N. Krueger, et al. Wirksamkeit und Dauerhaftigkeit von Bioziden in Bautenbeschichtungen. Bauphysik 34(4):170-182, 2012. https://doi.org/10.1002/bapi.201200021.

[10] J. R. Krentowski, P. Knyziak, M. Mackiewicz. Durability of interlayer connections in exter-nal walls in precast residential buildings. Engineering Failure Analysis 121:105059, 2021. http:

//doi.org/10.1016/j.engfailanal.2020.105059

[11] K. Kobetičová, R. Černý. Terrestrial eutrophication of building materials and buildings: An emerging topic in environmental studies. Science of The Total Environment 689:1316-1328, 2019. https://doi.org/10.1016/j.scitotenv.2019.06.423

[12] L. Graziani, E. Quagliarini. On the modelling of algal biofouling growth on nano- $\mathrm{TiO}_{2}$ coated and uncoated limestones and sandstones. Coatings 8(2):54, 2018. https://doi.org/10.3390/coatings8020054

[13] P. Raschle, R. Büchli. Algen und Pilze an Fassaden Ursachen und Vermeidung. 2nd ed. Fraunhofer IRB Verlag, 2006.

[14] K. Sedlbauer, et al. Prognoseverfahren zum biologischen Befall durch Algen, Pilze und Flechten an Bauteiloberflächen auf Basis bauphysikalischer und mikrobieller Untersuchungen. Band 77. Fraunhofer IRB Verlag, Holzkirchen, 2007.

[15] E. Barreira, et al. Hygrothermal Behavior, Building Pathology and Durability, chap. Biological Defacement of External Thermal Insulation Composite Systems, pp. 23-44. Springer-Verlag,, Berlin, Heidelberg, 2013. https://doi.org/10.1007/978-3-642-31158-1_2

[16] C. Gaylarde, M. R. Silva, T. Warscheid. Microbial impact on building materials: an overview. Materials and Structures 36(5):342-352, 2003. https://doi.org/10.1007/BF02480875. 
[17] L. Wadsö, et al. Biological applications of a new isothermal calorimeter that simultaneously measures at four temperatures. Journal of Thermal Analysis Calorimeter 104(1):119-126, 2011. https://doi.org/10.1007/s10973-010-1140-y

[18] K. Minarovičová, D. Dlhý. Environmentally safe system for treatment of bio corrosion of ETICS. MATEC Web of Conferences 146:03005, 2018. https://doi.org/10.1051/matecconf/201814603005

[19] E. Terpakova, A. Estokova. Analytical support in solving bio-corrosion of fasade system ETICS. Section green buildings technologies and materials. In 16th International Multidisciplinary Scientific GeoConference SGEM 2016,, pp. 33-40. 2016.

[20] M. Krus, D. Rösler. Hygrothermische Berechnung der Einsatzgrenzen unterschiedlicher Systeme bei der Aufdoppelung von Wärmedämmverbundsystemen. Bauphysik 33(3):142-149, 2011. https://doi.org/10.1002/bapi.201110017

[21] B. Belániová, N. Antošová, L. Šupejová. Solution of problems of ETICS with biocorrosion. MATEC Web of Conferences 146:03007, 2018.

https://doi.org/10.1051/matecconf/201814603007
[22] Tepelné posudky software Svoboda Teplo (Thermal assessments software Svoboda Teplo).

[23] E. Barreira, V. P. de Freitas. Importance of thermography in the study of ETICS finishing coatings degradation due to algae and mildew growth. In 10 DBMC - International Conference On Durability of Building Materials and Components, pp. 17-20. 2005.

[24] M. H. Künzel, M. Krus, C. Fitz, et al. Accelerated test procedure to assess the microbial growth resistance of exterior finishes. In 12th International Conference on Durability of Building Materials and Components 1, pp. 260-267. 2011.

[25] Z. Sternová, et al. Zásady navrhovania a zhotovovania zdvojenia ETICS. Technická informácia č. 3. Jaga group, Bratislava, 2016.

[26] STN 73 2901/01: 2015 Zhotovovanie vonkajších tepelnoizolačných kontaktných systémov (ETICS).

[27] E. Piecková, Z. Pivovarová, Z. Sternová, E. Droba. Building materials vs. fungal colonization - model experiments. Environmental Health Risk IV 11:71-78, 2007. https://doi.org/10.2495/EHR070081.

[28] ETAG 004: External composite thermal insulation systems with plaster (ETICS). 